\title{
Effect of name agreement on prefrontal activity during overt and covert picture naming
}

\author{
IRENE P. KAN and SHARON L. THOMPSON-SCHILL \\ University of Pennsylvania, Philadelphia, Pennsylvania
}

\begin{abstract}
In recent neuroimaging studies, various tasks have been used to examine prefrontal cortex involvement in semantic retrieval and selection. One such task, picture naming, has yielded inconsistent results across studies. One potential explanation for this inconsistency is that the magnitude of prefrontal activity during picture naming depends on the extent to which a given picture evokes a single reliable meaning. To test this hypothesis, fMRI activity in the prefrontal cortex was measured while subjects named pictures with either high or low name agreement. In Experiment 1, subjects named black-andwhite line drawings, either covertly or overtly. Across both modalities, we found more left inferior frontal gyrus (LIFG) activity when the subjects named low-agreement pictures than when they named high-agreement pictures. No significant difference in head movement was detected between the two modalities. In Experiment 2, we replicated the effect of name agreement on LIFG activity during picture naming, using black-and-white photographs. These results provide further support for the idea that the LIFG mediates selection among competing alternatives and suggest a means for understanding the naming deficits observed in nonfluent aphasia.
\end{abstract}

Our ability to retrieve stored information about objects, concepts, facts, and words (i.e., semantic memory) has been the subject of much inquiry by cognitive scientists and cognitive neuroscientists; in particular, recent years have seen an escalation in research in which the neural mechanisms that mediate the storage and retrieval of semantic knowledge have been investigated (for a review, see Thompson-Schill, 2003). Historically, data from neuropsychological studies have linked retrieval of semantic knowledge to the left temporal lobe (e.g., Hodges, Graham, \& Patterson, 1995; Hodges, Patterson, Oxbury, \& Funnell, 1992; Saffran \& Schwartz, 1994). However, a number of recent neuroimaging studies have suggested that the left prefrontal cortex may also be involved in semantic knowledge retrieval (e.g., Petersen, Fox, Posner, Mintun, \& Raichle, 1988; Wagner, Pare-Blagoev, Clark, \& Poldrack, 2001).

There is considerable evidence that blood flow to the left prefrontal cortex-specifically, the left inferior frontal

Portions of this research were presented at the Cognitive Neuroscience Society Eighth Annual Meeting. This research was supported by Grants NIH R01 MH60414 and NIH R01 MH67008 from the National Institute of Health, by a University of Pennsylvania Research Foundation grant, by a Searle Scholars Program award to S.L.T.-S., and by an NIH Predoctoral Training Grant in Behavioral and Cognitive Neuroscience awarded to I.P.K. We thank Jeris Minor and Amanda Van Scoyoc for assistance in data collection and Geoffrey Aguirre and Joseph Kable for assistance with data analysis. We also thank John Jonides, Robyn Oliver, and two anonymous reviewers for helpful comments on an earlier draft of this manuscript. Correspondence concerning this article should be addressed to I. P. Kan, Department of Psychology, University of Pennsylvania, 3720 Walnut Street, Philadelphia, PA 19104-6241 (e-mail: ikan@psych.upenn.edu). gyrus (LIFG) - increases when subjects engage in semantic retrieval tasks. These tasks include word generation (e.g., Petersen et al., 1988; Raichle et al., 1994), word categorization (e.g., Demb et al., 1995), and semantic monitoring (e.g., Démonet et al., 1992). If the LIFG indeed subserves semantic retrieval, one would expect this region to be recruited in all tasks that require retrieval of semantic knowledge. However, reports of LIFG involvement in some semantic tasks have been inconsistent. One such task that has produced ambiguous evidence is the picture-naming task.

In a typical picture-naming task, subjects are shown a series of pictures, and their task is simply to produce a name for each picture. This is considered a semantic task because it is widely assumed that generating a name for a picture requires obligatory access to the semantic system (e.g., Bookheimer, Zeffiro, Blaxton, Gaillard, \& Theodore, 1995; Caramazza, Hillis, Rapp, \& Romani, 1990; Levelt et al., 1991). Given this assumption, the task has been used to study a wide variety of cognitive phenomenon, including the structure and organization of the semantic system (e.g., Glaser, 1992; Warrington \& Shallice, 1984), the time course of lexical access in speech production (e.g., Levelt et al., 1991), lexical retrieval in aphasics (e.g., Goodglass \& Stuss, 1979; Kohn \& Goodglass, 1985), and the organization of the memory system in dementia patients (e.g., Robinson, Grossman, WhiteDevine, \& D'Esposito, 1996) and in normals (e.g., Ratcliff \& McKoon, 1996; Spitzer, Kwong, Kennedy, Rosen, $\&$ Belliveau, 1995). However, neuroimaging studies in which this task has been used have produced inconsistent results: Whereas some studies have reported robust LIFG activity during picture naming (e.g., Bookheimer 
et al., 1995; Murtha, Chertkow, Beauregard, \& Evans, 1999; Salmelin, Hari, Lounasmaa, \& Sams, 1994), others have failed to find significant LIFG activity (e.g., Etard et al., 2000; Sergent, Ohta, \& MacDonald, 1992). What is the basis for this discrepancy? Several possibilities present themselves. First, perhaps it is possible to bypass the semantic system when naming a picture. Thus, if semantic retrieval is not necessary, the LIFG will not be recruited. Second, as has been suggested by Wagner et al. (2001), perhaps the LIFG is recruited only when the retrieval process is controlled and effortful. That is, the LIFG is involved only when the retrieval process is not automatic. Thus, the inconsistent results may be attributable to variation in retrieval efforts across different experiments. Third, the LIFG may not in fact subserve general semantic memory retrieval but, rather, may be involved in some other mechanisms that are common to some of these studies. One such mechanism will be discussed in detail below.

The first possibility seems unlikely. Data from behavioral experiments have provided ample evidence that semantic knowledge is accessed during picture name retrieval. For example, Bajo (1988) reported a reliable semantic priming effect when picture stimuli were used. Specifically, subjects were faster at naming a target picture (e.g., bread) when a semantically related picture prime (e.g., biscuit) was presented prior to the target than when a semantically unrelated picture prime (e.g., broom) preceded the target. This pattern of data suggested that picture naming activated semantic knowledge that was associated with the concept (see also Lupker, 1988, McCauley, Parmelee, Sperber, \& Carr, 1980, and Sperber, McCauley, Ragain, \& Weil, 1979, for similar findings). In addition, recent neuroimaging (e.g., Murtha et al., 1999; Whatmough, Chertkow, Murtha, \& Hanratty, 2002) and cortical stimulation (e.g., Ilmberger, Eisner, Schmid, \& Reulen, 2001) studies have demonstrated that when subjects named pictures, brain areas that are typically involved in semantic retrieval were recruited (i.e., left temporal regions). Collectively, these data suggest that semantic knowledge activation and retrieval is obligatory when picture stimuli are identified.

These types of findings have been integrated into many theoretical models of picture naming. In fact, almost all accounts of picture naming incorporate a concept activation stage within their models (e.g., Fraisse, 1969; Glaser, 1992; Huttenlocher \& Kubicek, 1984; Levelt et al., 1991). For example, on the basis of a series of behavioral experiments designed to investigate the time course of lexical access in picture naming, Levelt et al. (1991) proposed a two-stage model of lexical retrieval: According to their model, an input concept is automatically generated upon perception of an object, and after perceptual analyses of the visual input, a set of semantically driven candidate lemmas become activated. A selection process then follows, from which only one of these semantically related alternatives will survive, and this is the only item that is encoded phonologically and, ultimately, articulated as a response. Fraisse (1969) proposed a similar account, which suggested that unlike word reading, picture naming is often associated with a degree of response uncertainty. In many cases, a given picture may be associated with multiple plausible responses. In order to select a target response, an individual must consult with contextual information (e.g., task instructions).

These models of picture naming highlight not only the role of automatic semantic retrieval in picture naming, but also the role of a postretrieval selection process. Since semantic retrieval during picture naming is generally considered to be an automatic process, and not an effortful search process, by these models, the second possibility proposed earlier seems irrelevant in this context.

The notion of a selection stage during picture naming is related to the third possible explanation offered above for the inconsistent neuroimaging results with this task: Perhaps the occasionally observed LIFG activity during picture naming reflects not semantic retrieval per se but, rather, this postretrieval selection process. To the extent that LIFG activity reflects selection demands, the inconsistencies in LIFG activation during picture naming might, in part, be attributable to unintentional variations in selection demands across picture-naming tasks or stimuli.

The association of selection with the LIFG has been demonstrated in both neuroimaging and neuropsychological studies. Thompson-Schill and colleagues (ThompsonSchill, D'Esposito, Aguirre, \& Farah, 1997; ThompsonSchill, D’Esposito, \& Kan, 1999; Thompson-Schill et al., 1998) postulated that LIFG activity is related to the demands of selection of information among competing alternatives, and not to general semantic retrieval per se. Their first test of this hypothesis utilized functional magnetic resonance imaging (fMRI; Thompson-Schill et al., 1997). Selection demands were manipulated in three semantic tasks that differed in terms of task demand (generation, classification, and comparison), stimulus type (pictures and words), and response type (covert production and binary decision). Across all three tasks, high selection trials had more competition from semantic alternatives than did low selection trials. Patterns of brain activation produced by these three tasks were compared within a single group of subjects. All three tasks showed effects of selection demands in overlapping regions in the LIFG, with local maxima for the three tasks located in the same superior-inferior plane and within a few millimeters of each other. The authors concluded that the magnitude of LIFG activity reflects the degree of selection among competing alternatives. In a subsequent fMRI study (Thompson-Schill et al., 1999), in which selection demands and retrieval demands were unconfounded, only the former were associated with the magnitude of LIFG activation. Furthermore, other investigators have reported similar effects of selection demands in the LIFG. For example, in an fMRI study, Barch, Braver, Sabb, and Noll (2000) demonstrated a dissociation 
between selection-dependent activity in the LIFG and conflict-dependent activity in the anterior cingulate.

Additional evidence in support of the selection hypothesis has come from a neuropsychological study of the necessity of the LIFG for selection or retrieval of semantic information. Thompson-Schill et al. (1998) examined the ability of patients with focal frontal lesions to perform a verb generation task under high and low selection demands. In this task, subjects were presented with concrete nouns (e.g., apple) and were asked to generate associated verbs (e.g., eat). If the LIFG is necessary for semantic retrieval, patients with focal lesions to the area would be expected to fail at this task. However, if the LIFG is necessary for selecting information among competing alternatives, patients with focal lesions to the area would be expected to show impairment only when selection demands are high (e.g., cat $\rightarrow$ purr, pet, meow, play), but not when selection demands are low (e.g., scissors $\rightarrow c u t$ ). Patients with focal damage to the LIFG performed within normal range on low selection items but produced significantly more errors than did control subjects on high selection trials. Furthermore, the number of selection-related errors was strongly correlated specifically with the degree of damage to the LIFG, but not with overall lesion volume. This pattern of impairments demonstrated that the LIFG is necessary for semantic retrieval only under conditions that place high demands on the ability to select among competing alternatives.

In the present study, we tested the hypothesis that the magnitude of LIFG activity during picture naming reflects variability in selection demands, as indexed by name agreement. Name agreement refers to the degree of concordance with which subjects name a given picture. For example, a picture with a name agreement of $100 \%$ means that all the subjects give the same name to a picture (e.g., book). On the other hand, a picture with $76 \%$ name agreement means that only $76 \%$ of the subjects provide the same name for a given picture (e.g., stove) and the other $24 \%$ give alternative responses (e.g., oven, range, etc.).

In order to test this hypothesis, we made the following two assumptions. First, we assumed that picture naming involves a selection process. Second, we assumed that demands for this selection process are variable and that name agreement is inversely related to selection demands. In other words, selection demands should be higher when multiple names apply to a single picture than when a single reliable name comes to mind. For example, consider a picture of a book, as compared with a picture of a stove: In most cases, the picture of a book will evoke a single reliable response (i.e., high name agreement). In contrast, names such as stove, oven, and range may all come to mind for the picture of a stove (i.e., low name agreement). Thus, when an individual must make a response, demands for selection are lower when naming a picture of a book than when naming a picture of a stove. This assumption is consistent with Levelt et al.'s (1991) two-stage model, described earlier: During picture nam- ing, a semantic cohort is automatically activated, and a selection process chooses among competing alternatives. One behavioral implication of Levelt et al.'s (1991) two-stage model and Fraisse's (1969) model is that the more competing alternatives there are for a given picture, the longer it will take to select an appropriate response. Accordingly, Kremin, Hamerel, Dordain, De Wilde, and Perrier (2000) demonstrated that name agreement and picture-naming latency are negatively correlated. Unfortunately, many of the picture-naming neuroimaging studies neglected to report name agreement data for their stimuli (e.g., Bookheimer et al., 1995; Sergent et al., 1992). It is conceivable that the degree of selection demands inadvertently varied from study to study and, as a consequence, differing degrees of LIFG involvement occurred. In the absence of relevant data for a post hoc analysis of this hypothesis, we sought direct evidence from two fMRI experiments designed to compare LIFG activity during the naming of pictures with high and low name agreement.

A secondary purpose of the first experiment was to assess the feasibility of collecting verbal responses in the fMRI environment. The obvious advantage of collecting verbal responses is the ability to determine whether subjects carried out the task correctly. Asking subjects to make overt responses, Barch et al. (2000) found that in a verb generation task, 3 of the 14 subjects performed the task incorrectly (e.g., generated a verb when asked to read baseline words). Furthermore, in an event-related design, trials on which subjects provided incorrect answers can also be removed or analyzed separately (e.g., de Zubicaray, Wilson, McMahon, \& Muthiah, 2001). Despite these advantages, this approach has not been widely adopted because of the potential artifact associated with overt responding in $\mathrm{fMRI}$. The general concern is an increased level of head movement associated with overt responding.

In two fMRI experiments that compared covert and overt responding, Barch et al. (2000; Barch et al., 1999) reported minimal absolute head movement associated with overt responding. By acquiring two consecutive sets of brain images per trial, Barch et al. (1999) were able to discard the images acquired during the actual verbal responses and, thus, minimized absolute head movement throughout the scan. In the present experiment, we used a slightly different technique in image acquisition. By extending repetition time (TR), grouping the pulses at the beginning of the acquisition period, and carefully timing stimulus onset, the subjects' responses should almost always occur during the time period in which data are not being collected (see the Image Acquisition section below for more details).

In the following experiments, we explored a potential explanation for inconsistent observations of LIFG activity in previous picture-naming studies. Specifically, we examined the effect of name agreement on LIFG activity. We proposed that prefrontal activity during picture naming may be modulated by the number of competing 
name alternatives evoked by a picture. As was stated earlier, we predicted higher LIFG activity in the low name agreement (high selection) condition than in the high name agreement (low selection) condition. In addition to investigating the selection effects in picture naming, we also examined whether these selection effects differed as a function of response modality in Experiment 1. In Experiment 2, we assessed the generalizability of our findings to a different class of stimuli.

\section{EXPERIMENT 1}

In Experiment 1, we examined the hypothesis that LIFG activity is modulated by picture name agreement. Subjects named simple black-and-white line drawings, either covertly or overtly, in an fMRI experiment. On the basis of published picture name agreement norms (Snodgrass \& Vanderwart, 1980), pictures were classified as either high or low in name agreement. In sum, a 2 (name agreement) $\times 2$ (response modality) within-subjects design was used. Thus, we were able to measure both the effect of varying name agreement on fMRI activity in the LIFG during picture naming and the extent to which this effect varied as a function of response modality.

\section{Method}

\section{Subjects}

Eight paid volunteers from the University of Pennsylvania participated in this study. The subjects were 5 males and 3 females, $18-25$ years of age (mean age $=20.3$ years). All the subjects met the following inclusion criteria: They were (1) high school educated, (2) native English speakers, and (3) right-handed. General exclusionary criteria were (1) history of neurological or psychiatric illness or (2) current use of medication affecting the central nervous system (e.g., psychotropic drugs). Informed consent was obtained from all the subjects, and each subject was paid \$20 for his or her participation.

\section{Materials}

A total of 192 drawings were used in the experiment, and they were divided into two sets-high name agreement or low name agreement - on the basis of the name agreement norms reported by Snodgrass and Vanderwart (1980). Each picture was presented only once within each session. Mean name agreement for high name agreement pictures was $98.38 \%$ (range, 95\%-100\%), and mean name agreement for low name agreement pictures was $71.42 \%$ (range, 33\%-86\%). Unpaired $t$ tests revealed a significant difference in name agreement percentages between the two sets of pictures $[t(190)=20.37, p<.001]$ and a significant difference in mean picture complexity [2.80 for high agreement and 3.10 for low agreement; $t(190)=-2.31, p<.05]$. The two sets of pictures were matched on mean familiarity [3.41 for high and 3.15 for low; $t(190)=$ $1.88, p>.05]$ and median Kučera-Francis written frequency for picture names [ 10.50 for high and 10.00 for low; $t(173)=0.39, p=.70$ ], on the basis of the normative data reported by Snodgrass and Vanderwart. Kučera-Francis written frequency was not available for 17 lowagreement items.

To create the abstract line drawings used in the baseline condition, the set of 192 line drawings used in the picture-naming task were distorted. Specifically, the following distortion filters in Photoshop 6.0 were used: wavelength $=10,90$; amplitude $=5,35$; type $=$ sine; repeat edge pixels. Pilot testing indicated that the distorted pictures were no longer identifiable as real objects. A rectangle was superimposed on top of half of the drawings, and noth- ing was added to the other half of the pictures. Each distorted picture was presented only once within each session.

\section{Procedure}

Picture-naming task. Each subject was presented with a series of simple black-and-white line drawings, one at a time, and was asked to identify the object depicted. In the overt condition, the subjects made their responses aloud, and in the covert condition, the subjects indicated their responses with bilateral buttonpresses on the middle two buttons of a four-button response pad. The subjects were told to respond as soon as they had generated a name for the picture and to do nothing if they were unable to generate a name within the time limit.

Baseline yes/no judgment task. In the baseline condition, the subjects were presented with a series of black-and-white abstract drawings, and on each trial, the subject's task was to determine whether a rectangular box was present. In the overt condition, the subjects made their "yes"/"no" responses aloud, and in the covert condition, the subjects indicated their responses with bilateral buttonpresses. Half of the subjects pressed the middle two buttons for a yes response and the outer two buttons for a no response; the other half of the subjects used the reverse configuration. The subjects were told to respond as quickly as possible without sacrificing accuracy.

Trial composition. Each trial consisted of an image acquisition period, fixation, stimulus presentation, and a response period. The beginning of each trial was synchronized with the onset of the image acquisition period. After the subjects had looked at a blank screen with a black background for $1,200 \mathrm{msec}$, a fixation cross was presented in the middle of the screen for $150 \mathrm{msec}$. At the offset of the fixation point, the stimulus was presented, which remained on the screen for $650 \mathrm{msec}$, and the subjects were given 2,000 msec to make a response. In order to minimize signal changes induced by movement associated with overt responding, each stimulus was presented near the end of the image acquisition period so that the subjects' responses were made when images were not being acquired (see Figure 1A).

Trial blocking. A blocked design was implemented. Six trials made up each experimental block, and 16 blocks of trials made up each experimental run. The subjects always responded in the same modality (i.e., either covert or overt) within the same run. In each experimental run, alternating blocks of picture-naming trials and baseline trials were presented. Across the picture-naming blocks, each block alternated between the high name agreement and the low name agreement conditions (e.g., high agreement, baseline, low agreement, baseline, high agreement, baseline, low agreement, etc.; see Figure 2). Within each run, there were 96 trials: 24 high agreement trials, 24 low agreement trials, and 48 baseline trials. There were two covert runs and two overt runs, for a total of 384 trials in the entire session. The order of covert and overt runs was counterbalanced across subjects, and the order of high-agreement and lowagreement blocks was counterbalanced within subjects.

To ensure that the subjects would perform the correct task and that they would respond in the proper modality, a task prompt was shown at the beginning of each block (Picture Naming or Box Present?), and a modality prompt was shown at the beginning of each run (Respond Aloud or Button Press).

Stimulus presentation. Using PsyScope software (Cohen, MacWhinney, Flatt, \& Provost, 1993), the stimuli were presented with a Macintosh G3 Powerbook connected to an Avotec Silent Vision visual presentation system (Stuart, FL, www.avotec.org). A four-button fiber optic response pad connected to the computer was used to record the subjects' buttonpress responses in the covert condition, and a Silent Scan auditory presentation system was used to transmit the subjects' verbal responses in the overt condition.

Image acquisition. Following the acquisition of saggital and axial T1-weighted localizer images, gradient echo, echoplanar 
$(A)$

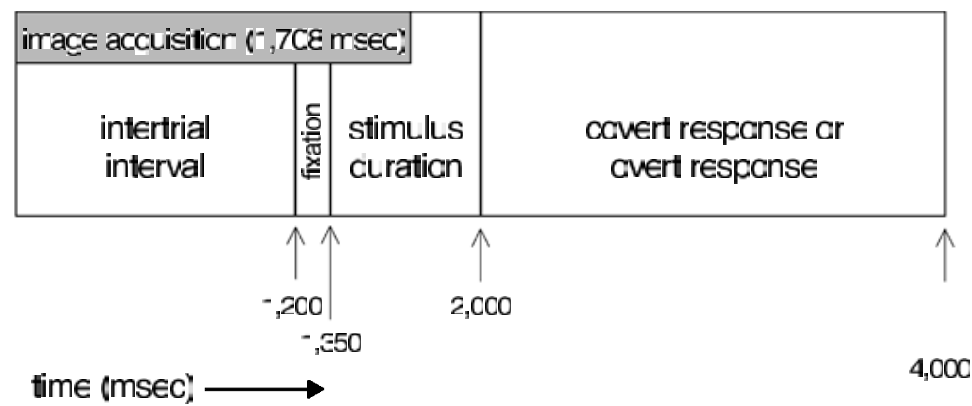

(B)

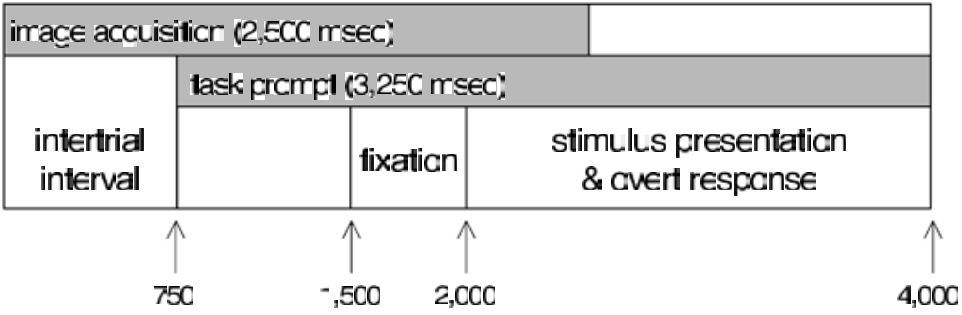

time (msec)

Figure 1. Trial composition for (A) Experiment 1 and (B) Experiment 2.

fMRI was performed in 21 contiguous $5-\mathrm{mm}$ axial slices $(\mathrm{TR}=$ $4,000, \mathrm{TE}=50,64 \times 64$ pixels in a $24-\mathrm{cm}$ field of view, voxel size $=3.75 \times 3.75 \times 5 \mathrm{~mm}$ ), using a 1.5-T GE Signa system equipped with a fast gradient system and the standard quadrature head coil. To minimize head motion, foam padding was placed between the subject's head and the head coil. Twenty seconds of "dummy" gradient and rf pulse preceded data acquisition to approach steady-state magnetization.

Image processing. Off-line data processing was performed using VoxBo software (www.voxbo.org). After image reconstruction, the data were sinc interpolated in time to correct for the fMRI acquisition sequence. A slicewise motion compensation method was utilized to remove spatially coherent signal changes by the application of a partial correlation method to each slice in time (Zarahn, Aguirre, \& D'Esposito, 1997). Additional motion detection and correction was undertaken using a six-parameter, rigidbody transformation. None of the subjects had translational motion that exceeded $2 \mathrm{~mm}$ in any plane or angular motion that resulted in more than a 2-mm displacement.

Image analyses. Voxelwise analysis was performed on each subject's data, using a general linear model for serially correlated error terms (Worsley \& Friston, 1995), and an estimate of intrinsic temporal autocorrelation was included within the model (Aguirre, Zarahn, \& D'Esposito, 1997). Furthermore, sine and cosine regressors for frequencies below that of the task $(0.0156 \mathrm{~Hz})$ were also included in the general linear model. Temporal data were smoothed with an empirically derived estimate of the hemodynamic response of the fMRI system; this analysis has been empirically demonstrated to hold the mapwise false positive rate at or below tabular values (Zarahn et al., 1997).

A random effects group analysis of normalized data from all the subjects was also performed. For each individual, we derived an unthresholded beta-map for the direct contrast of picture-naming trials and baseline trials. These main effect beta-maps were then normalized into a standard coordinate space, using a 12-parameter affine transformation with nonlinear deformations. Normalization parameters were derived from each subject's high-resolution anatomical scan. The maps were then spatially smoothed by convolution with a three-dimensional Gaussian kernel that has a FWHM of $1.5 \times 1.5 \times 2.0$ (in voxels).

After smoothing and normalization, we defined five functionalanatomical regions of interest (ROI): the LIFG, the right inferior frontal gyrus (RIFG), the left temporal lobe, the right temporal lobe, and the anterior cingulate. Each of these ROIs consisted of voxels that demonstrated signif icant picture-naming effects within each anatomically defined region. These ROIs were then used to examine the effects of name agreement in each response modality. All voxels within each functionally-anatomically defined ROI were included in a contrast analysis between high name agreement trials and low name agreement trials.

\section{Results}

\section{Behavioral results}

The subjects' responses were compared with the standard names provided by Snodgrass and Vanderwart (1980), so that an index of the level of agreement for each set of drawings could be calculated. A response (e.g., book) was considered a match if it was the most common name given in the Snodgrass and Vanderwart norms. Overall agreement percentages across subjects and across items were then calculated.

As a group, the subjects produced significantly higher response agreement in the high-agreement condition $(M=94.8 \%)$ than in the low-agreement condition $(M=$ $79.9 \%)$, and the difference between conditions was significant $[t(7)=6.95, p<.001]$. The name agreement effect was also significant across items [high name 


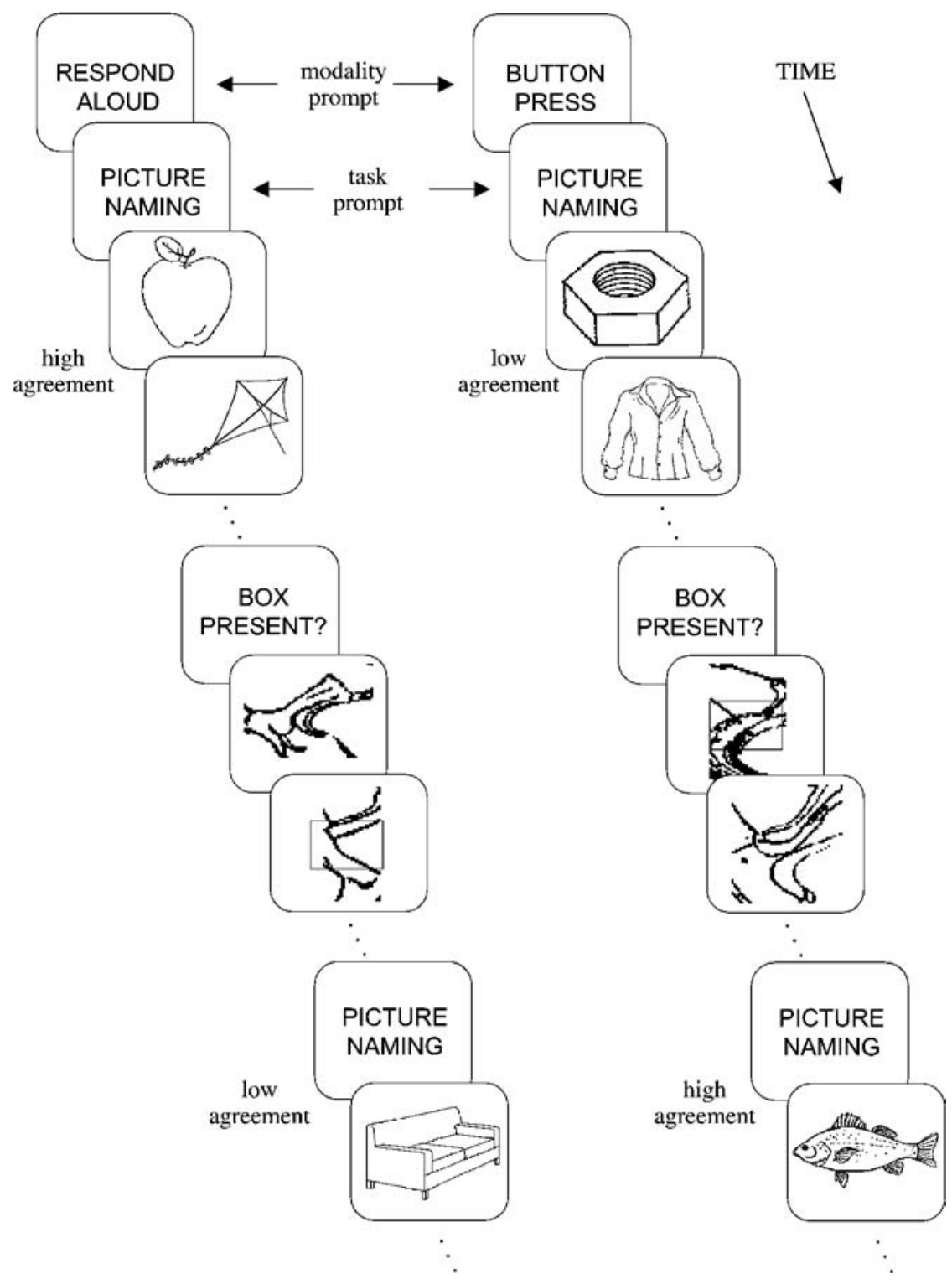

Figure 2. Pictorial depiction of trial types in Experiment 1.

agreement items, $M=94.0 \%$; low name agreement items, $M=79.2 \% ; t(190)=5.04, p<.001]$. This confirmed that the name agreement manipulation was effective. These data were derived from only the overt trials, because it was not possible to evaluate the subjects' naming responses in the covert condition. However, across all of the counterbalancing conditions, all the pictures were included in this analysis. Performance on baseline items derived from high-agreement pictures did not differ from performance on baseline items derived from low-agreement pictures $[M$ diff $=-0.30 ; t(7)=$ $-0.33, p=$ n.s.].

Due to technical constraints, we were unable to collect reaction time (RT) data from these subjects in the overt condition. Therefore, behavioral data were collected from an independent group of 20 subjects outside the scanner. These subjects were drawn from the same population as the experimental subjects. Response agreement and RTs from these subjects were compared between conditions. Name agreement manipulation was again shown to be effective, both across subjects and across items. A paired $t$ test across subjects' responses showed a significant difference between the high name agreement $(M=93.4 \%)$ and the low name agreement $(M=62.6 \%)$ conditions $[t(19)=11.9, p<.001]$. An unpaired $t$ test across items also showed a significant difference between the high name agreement $(M=95.8 \%)$ and the low name agreement $(M=68.0 \%)$ conditions 


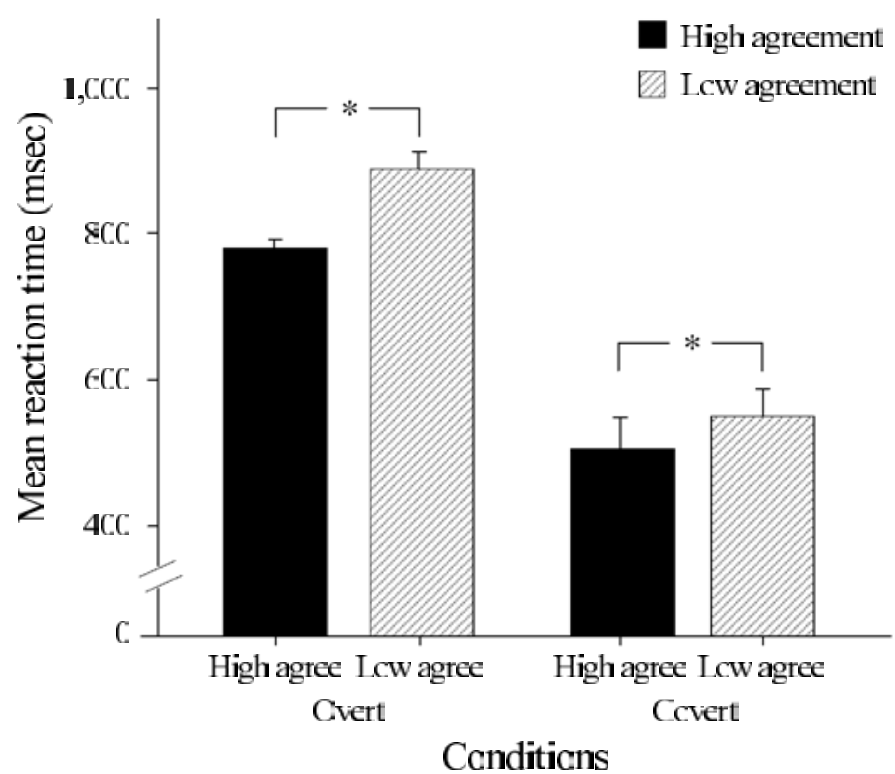

Figure 3. Mean reaction time (in milliseconds) as a function of experimental conditions in a separate behavioral experiment conducted outside of the scanner. A group of 20 independent subjects were recruited. One standard error of the mean is indicated above each bar.

$[t(190)=9.98, p<.001]$. Furthermore, the subjects' performances on the two baseline conditions were comparable $[t(19)=0.01, p=$ n.s.]. Again, the agreement data were derived from the overt trials only.

To examine the RT data, a 2 (modality) $\times 2$ (agreement) repeated measures analysis of variance was performed. A significant modality $\times$ agreement interaction was found $[F(1,19)=5.66, p=.03]$. As is depicted in Figure 3, this is an ordinal interaction; that is, the magnitude of the agreement effect (low name agreement RT minus high name agreement RT) differed between the two response modalities, but the direction of the effect was the same. Specifically, the agreement effect was larger in the overt condition $(M$ diff $=107 \mathrm{msec})$ than in the covert condition $(M \operatorname{diff}=44 \mathrm{msec})$. Furthermore, pairwise $t$ tests showed that both of these agreement effects were statistically significant $(p s<.003)$.

\section{fMRI Results}

To identify a significant main effect of picture naming, all the picture trials were compared with all the baseline trials. In both conditions, all 8 subjects showed significant increases in fMRI activity during the picture-naming condition, relative to the baseline condition (mapwise $t>3.5$ ). Specifically, in the covert condition, all 8 subjects showed increases in fMRI activity during the picture generation condition, as compared with the baseline condition, in the following areas: bilateral temporal areas, bilateral frontal areas, the right paracentral lobule, and the anterior cingulate. In the overt condition, all 8 subjects showed increases in fMRI activity during the pic- ture generation condition, as compared with the baseline condition, in these areas: bilateral temporal areas, the left frontal lobe, bilateral occipital areas, bilateral parietal areas, and the anterior cingulate.

The regions included in the functional-anatomical ROI analysis are illustrated in Figure 4. As a group, in the covert condition, the subjects showed greater LIFG activity for the low name agreement (high selection) condition than for the high name agreement (low selection) condition $[M$ effect size $=2.29 ; t(7)=4.56, p=.03$ ] In the overt condition, the subjects also showed greater LIFG activity for the low name agreement (high selection) condition than for the high name agreement (low selection) condition $[M$ effect size $=2.32 ; t(7)=2.32, p=$ .03]. To investigate whether the selection effect is specific to the LIFG, four additional regions were examined: the RIFG, the left temporal lobe, the right temporal lobe, and the anterior cingulate. The RIFG would allow for exploration of a potential laterality effect, and the bilateral temporal areas were chosen because these areas are typically associated with retrieval of semantic knowledge via pictorial stimuli. Furthermore, the anterior cingulate was included because previous studies had shown its involvement in conflict monitoring and evaluation, which is a process closely related to selection (Barch et al., 2000; Carter et al., 2003). In both response modalities, among the five functional-anatomical ROIs, the selection effect was significant in the LIFG only (see Table 1). Although the selection effect in the anterior cingulate in the overt condition was significant at $p<.05$, it did not survive our correction for multiple comparisons. With 
(A) Covert Condition

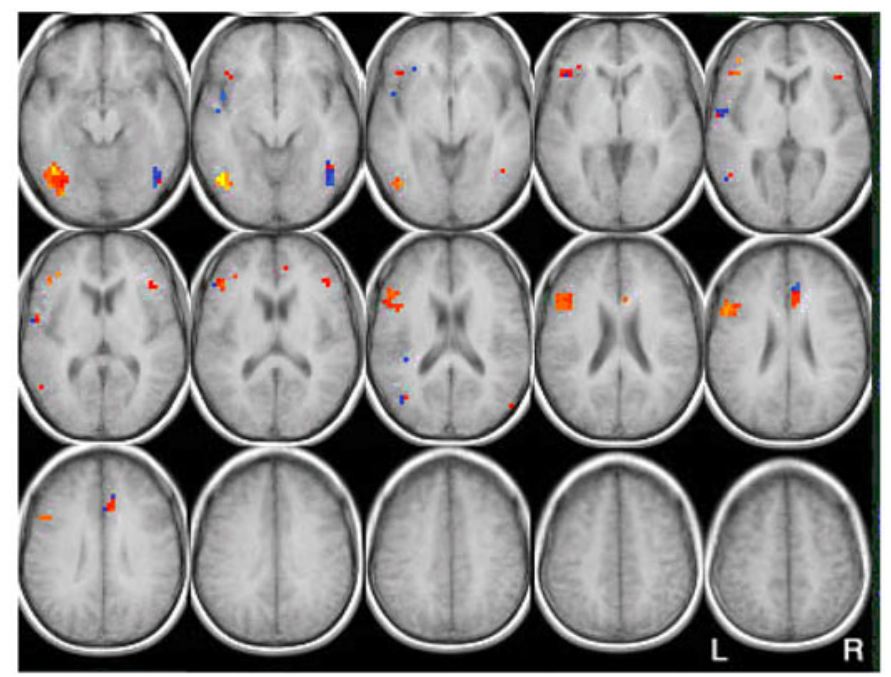

(B) Overt Condition

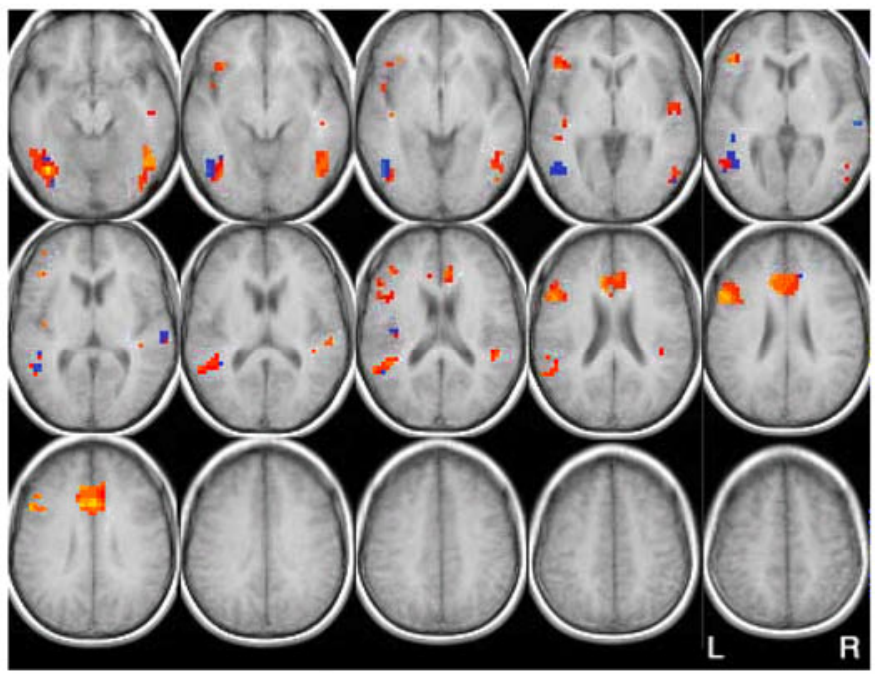

Figure 4. Functionally-anatomically defined regions of interest in the left inferior frontal gyrus, the right inferior frontal gyrus, the left temporal lobe, the right temporal lobe, and the anterior cingulate. Panel $A$ portrays data from the covert condition, and panel $B$ portrays data from the overt condition. All voxels depicted demonstrated a significant main effect of picture naming. Orange/red, low name agreement $>$ high name agreement; blue, high name agreement $>$ low name agreement.

four post hoc ROIs (i.e., the RIFG, the left temporal lobe, the right temporal lobe, and the anterior cingulate), the corrected threshold was $p<.01$.

\section{Mean Geometric Displacement}

To determine potential artifacts related to head movement, mean geometric displacement of images was calculated for each subject. This index indicates the absolute displacement of each image from the reference image. The first image of each run was designated as a reference image, and the absolute displacement of each subsequent image from the reference image was calculated. Thus, a total of 95 comparisons were performed for each run, and a total of 190 comparisons were made for each response modality. Averaged across the 8 subjects, the mean geometric displacement values were $0.18 \mathrm{~mm}$ for the covert condition and $0.16 \mathrm{~mm}$ for the overt condition. A pairwise $t$ test did not show a significant difference in mean geometric displacement between the two groups $[t(7)=0.75, p=.48]$. 
Table 1

Random Effects Group Analysis of Five Separate FunctionallyAnatomically Defined Regions of Interest in Experiment 1 (Low Name Agreement - High Name Agreement)

\begin{tabular}{lcc}
\hline & \multicolumn{2}{c}{ Response Modality } \\
\cline { 2 - 3 } \multicolumn{1}{c}{ Region of Interest } & $\begin{array}{c}\text { Overt Responding } \\
\text { (Mean Effect Size) }\end{array}$ & $\begin{array}{c}\text { Covert Responding } \\
\text { (Mean Effect Size) }\end{array}$ \\
\hline Left inferior frontal gyrus & $t(7)=2.32^{*}$ & $t(7)=2.29^{*}$ \\
Right inferior frontal gyrus & no active voxels & $t(7)=0.41$ \\
Left temporal lobe & $t(7)=1.78$ & $t(7)=1.81$ \\
Right temporal lobe & $t(7)=1.82$ & $t(7)=-0.41$ \\
Anterior cingulate & $t(7)=2.35^{*}$ & $t(7)=0.61$ \\
\hline
\end{tabular}

$* p<.05$.

\section{Discussion}

In Experiment 1, we examined the hypothesis that the degree of prefrontal activity during picture naming is dependent on the extent to which a given picture evokes a single reliable meaning. We observed greater activity in the LIFG during naming of pictures with low name agreement (high selection) than for those with high name agreement (low selection). This pattern of data was consistent across both response modalities. Furthermore, we also observed a marginal selection effect in the anterior cingulate, but only when the subjects named the pictures overtly. We will explore the implications of these data below in the General Discussion section.

The secondary objective of this study was to examine the practicality of collecting overt responses in an fMRI setting. One potential artifact associated with overt responding in fMRI is increased head movement. Consistent with findings reported by Barch et al. (2000; Barch et al., 1999), we found minimal absolute head movement in the overt condition. In fact, the amount of absolute head movement was comparable between the two response modalities. Thus, it seems that collecting verbal responses in $\mathrm{fMRI}$ is more plausible than was previously thought. In addition to being able to assess whether the subjects complied with our task instructions, we were also able to evaluate and confirm our selection demand manipulation empirically.

\section{EXPERIMENT 2}

In Experiment 2, we attempted to generalize our findings to a different set of stimuli. Although the black-andwhite line drawings (Snodgrass \& Vanderwart, 1980) used in Experiment 1 have been widely used in many different experiments, it is possible that black-and-white line drawings are inherently ambiguous and, thus, may lead to potentially superfluous agreement and selection effects. In Experiment 2, we examined this potential confound by replicating Experiment 1 with photographs of real objects. Aside from a few exceptions-stimulus type and response modality-we employed essentially the same design in Experiment 2 as that in Experiment 1.

\section{Method}

\section{Subjects}

Ten paid volunteers from the University of Pennsylvania participated in this study. The subjects were 4 males and 6 females, 18-25 years of age (mean age $=21.3$ years). Six were left-handed and 4 were right-handed, as determined by the Edinburgh Handedness Inventory (Oldfield, 1971). The inclusion of left-handed subjects will be the topic of a separate report and will not be discussed in this article. All the subjects met the following inclusion criteria: They were high school educated and were native English speakers. The same exclusionary criteria as those used in Experiment 1 also applied here. Informed consent was obtained from all the subjects, and each subject was paid $\$ 35$ for his or her participation.

\section{Materials}

A total of 144 black-and-white photographs of real objects, gathered from various sources on the Internet, were used in the experiment. The photographs were divided into two sets-high name agreement or low name agreement-on the basis of norms collected in a Web-based pilot experiment $(n=32)$. In the pilot experiment, the subjects were shown a total of 207 black-and-white photographs and were asked to name each picture. The experiment was self-paced. Name agreement for each picture was calculated, and the data were used to facilitate stimulus selection.

A final set of 144 photographs was selected; mean name agreement for high name agreement photographs was $95.83 \%$ (range, $88 \%-100 \%$ ), and mean name agreement for low name agreement photographs was $63.42 \%$ (range, 34\%-88\%). An unpaired $t$ test revealed a significant difference in name agreement percentages between the two sets of photographs $[t(142)=18.97, p<.001]$.

In a second pilot experiment, 12 additional subjects named the set of 144 photographs, one at a time, and their RTs were collected. Across subjects, the mean RT for high name agreement photographs was $1,004 \mathrm{msec}$ and the mean RT for low name agreement photographs was $1,153 \mathrm{msec}$. A paired $t$ test revealed a significant difference in mean RTs between the two sets of photographs $[t(11)=$ $5.83, p<.001]$, and this difference was also significant across items $[t(142)=5.54, p<.001]$.

As in Experiment 1, we used a set of abstract photographs in the baseline condition. The abstract photographs were created with the following distortion filters in Photoshop 7.0: number of generators $=5$; wavelength $=$ minimum of 10 and a maximum of 50; amplitude $=$ minimum of 5 and a maximum of 60 ; type $=$ sine; repeat edge pixels. The same rectangle detection task as that in Experiment 1 was used.

\section{Procedure}

The general procedure was identical to that in Experiment 1, with the following exceptions: response modality, trial composition, stimulus presentation equipment, image acquisition, and image processing. Only one response modality (overt) was included in this experiment. Furthermore, the trial composition was slightly different.

Trial composition. Each trial consisted of an image acquisition period, a task prompt, fixation, stimulus presentation, and a response period. The beginning of each trial was synchronized with the onset of the image acquisition period. After the subjects had looked at a blank screen with a white background for $750 \mathrm{msec}$, a task prompt (e.g., Name or Box?) was presented and remained on the screen for the remainder of the trial. A fixation cross was presented in the middle of the screen $750 \mathrm{msec}$ after the onset of the task prompt for $500 \mathrm{msec}$. At the offset of the fixation point, the photograph was presented, which remained on the screen for the rest of the trial $(2,000 \mathrm{msec})$. In order to minimize signal changes induced by movement associated with overt responding, each stimulus was presented near the end of the image acquisition period, so that the subjects' responses were made when images were not being 


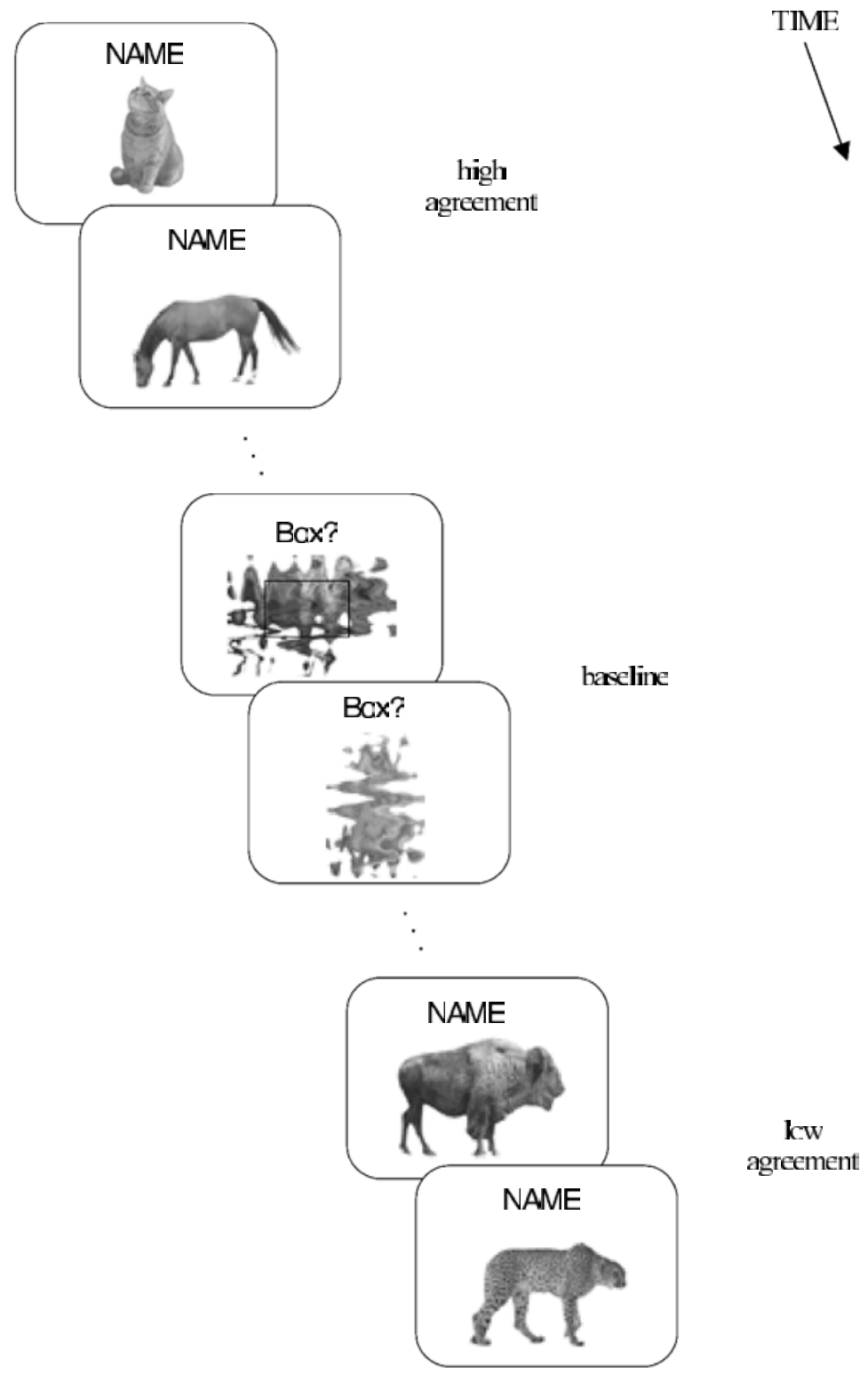

Figure 5. Pictorial depiction of trial types in Experiment 2.

acquired (see Figure 1B). Lastly, with the exception of eliminating presentation of a task prompt at the beginning of each block, trial blocking was the same as that in Experiment 1 (see Figure 5).

Stimulus presentation. Using PsyScope software (Cohen et al., 1993), the stimuli were presented with a Macintosh G3 Powerbook connected to an Epson 8100 3-LCD projector, which was housed inside a custom RF shield box. The image was projected onto a Mylar rear projection screen at the back of the scanner bore, and the subjects viewed the image through a mirror mounted on the head coil. The subjects' overt responses were transmitted via an Avotec Silent Scan auditory presentation system (Stuart, FL, www. avotec.org).

Image acquisition. Following the acquisition of saggital and axial T1-weighted localizer images, echoplanar fMRI was performed in 42 contiguous $3-\mathrm{mm}$ axial slices $(\mathrm{TR}=4,000$, $\mathrm{TE}=$
$30 \mathrm{msec}, 64 \times 64$ pixels in a $24-\mathrm{cm}$ field of view, voxel size $=3 \times$ $3 \times 3 \mathrm{~mm}$ ), using a 3.0 Tesla Siemens Trio system and a USA Instruments 4-channel head coil. To minimize head motion, foam padding was placed between the subject's head and the head coil. Twenty seconds of "dummy" gradient and rf pulse preceded data acquisition to approach steady-state magnetization.

Image processing. The procedures involved in off-line data processing were identical to those described in Experiment 1, with the exception of normalization. In Experiment 2, raw data for all the runs from each subject were transformed to standardized MNI space (Evans et al., 1993).

The procedures involved in the random effects group analysis were similar to those described in Experiment 1. In Experiment 2, normalization was performed on each individual's raw data prior to group analysis. For each individual, we derived an unthresholded 
Table 2

Random Effects Group Analysis of Five Separate FunctionallyAnatomically Defined Regions of Interest in Experiment 2 (Low Name Agreement - High Name Agreement)

\begin{tabular}{lcc}
\hline \multicolumn{1}{c}{ Region of Interest } & Mean Effect Size & $p$ Value \\
\hline Left inferior frontal gyrus & $t(9)=2.22$ & .05 \\
Right inferior frontal gyrus & $t(9)=1.06$ & .16 \\
Left temporal lobe & $t(9)=0.49$ & .32 \\
Right temporal lobe & $t(9)=0.53$ & .31 \\
Anterior cingulate & $t(9)=1.26$ & .11 \\
\hline
\end{tabular}

beta-map for the direct contrast of picture-naming trials and baseline trials. The maps were then spatially smoothed by convolution with a three-dimensional Gaussian kernel that had a FWHM of 2.67 $\times 2.67 \times 3.00$ (in millimeters).

After smoothing and normalization, we defined a functionalanatomical ROI in the LIFG. As in Experiment 1, in order to determine the specif icity of the agreement effect, we examined four additional regions: the RIFG, the left temporal lobe, the right temporal lobe, and the anterior cingulate. The ROIs consisted of voxels that demonstrated significant picture-naming effects. These ROIs were then used to examine the effects of name agreement. All voxels within each functionally-anatomically defined ROI were included in two contrast analyses between high name agreement trials and baseline trials and between low name agreement trials and baseline trials.

\section{Results}

\section{Behavioral Results}

The subjects' responses were compared with the names collected in the norming study, so that an index of agreement for each set of photographs could be calculated. The procedure used to calculate name agreement was identical to that in Experiment 1.

A paired $t$ test of the subjects' response agreements revealed a significant difference between the high name agreement $(M=85.8 \%)$ and the low name agreement $(M=$ $54.7 \%$ ) conditions $[t(9)=18.34, p<.001]$, and this difference was also significant across items $[t(142)=6.97$, $p<.001]$. This confirmed that the name agreement manipulation was effective. Performance on baseline items derived from high-agreement photographs $(M=99.7 \%)$ were compared with performance on baseline items derived from low-agreement photographs $(M=99.8 \%)$. No difference was found on response accuracy between the two baseline conditions $[t(9)=0.43, p=$ n.s.].

\section{fMRI Results}

To identify a significant main effect of picture naming, all the picture trials were compared with all the baseline trials. All 10 subjects showed significant increases in $\mathrm{fMRI}$ activity during the picture-naming condition, relative to the baseline condition, in the following areas: bilateral temporal areas, bilateral frontal areas, bilateral occipital areas, bilateral parietal areas, and the anterior cingulate. For the remainder of the discussion, we will focus only on activity in the LIFG, because that was the only area that showed a significant name agreement effect in Experiment 1 (see Table 2).
As a group, the subjects showed greater LIFG activity for the low name agreement (high selection) condition, as compared with baseline ( $M$ effect size $=6.48$ ), than for the high name agreement (low selection) condition, as compared with baseline ( $M$ effect size $=5.68)$. A pairwise comparison revealed a significant difference between the two conditions $[M$ effect size diff $=0.80$; $t(9)=2.22, p=.05]$.

\section{Mean Geometric Displacement}

The algorithm used to calculate mean geometric displacement was identical to that used in Experiment 1, with the exception of the number of images included in the comparison. A total of 95 comparisons were performed for each run, and a total of 285 comparisons were made for each subject. Averaged across all 10 subjects, the mean geometric displacement value was $0.20 \mathrm{~mm}$.

\section{Discussion}

In Experiment 2, we replicated the finding that activity in the LIFG is modulated by selection demands, which we manipulated by varying picture name agreement. Furthermore, we have extended our initial finding to a different set of stimuli-black-and-white photographs of real objects. In other words, the selection effects observed in Experiment 1 cannot be attributed to the potential ambiguity present in black-and-white line drawings or to other idiosyncratic differences between the items used in the first experiment.

\section{GENERAL DISCUSSION}

In both experiments, we observed that activity in the LIFG during picture naming was affected by picture name agreement. There are a number of possible interpretations for this finding: (1) LIFG activity is related to the degree of semantic retrieval required, (2) LIFG activity is modulated by the degree of task preparation involved, and (3) that LIFG activity is related to the demands of selection of information among competing alternatives. In the following section, we will explore each of these possibilities and will argue that the last explanation is a more viable account for previous discrepant findings regarding LIFG activity during picture naming. We will also consider the idea that the marginally significant selection effect found in the anterior cingulate in Experiment 1's overt condition may suggest that selection occurs at two different levels: Whereas LIFG activity correlates with selection on a representation level, anterior cingulate activity correlates with selection on a response level.

One possible alternative explanation of our data is that selection demands and semantic retrieval demands are confounded and that the observed difference in LIFG activity between the high name agreement and the low name agreement conditions actually reflects the degree of semantic retrieval required. After all, the definition of 
name agreement is intertwined with the number of semantic alternatives available. Thus, the more alternatives there are, the more semantic retrieval may be expected (Levelt et al., 1991). For example, when low agreement items, such as blouse, are named, more semantic retrieval is expected, because semantic cohorts, such as shirt and top, are also retrieved (see Figure 2 for the corresponding line drawing). On the other hand, when a high agreement item, such as book, is named, only one concept will be activated. Therefore, it may be possible to attribute the difference in LIFG activity to the differential amount of semantic retrieval required. Although data from previous experiments that dissociated semantic retrieval and selection demands help discount this explanation (Thompson-Schill et al., 1997; ThompsonSchill et al., 1999), it remains a possibility.

However, this explanation seems to be an unlikely account of the present data. If the selection effect observed in the LIFG indeed reflects a differential amount of semantic retrieval, we should also detect this difference in the temporal lobes, which have traditionally been associated with the retrieval of semantic knowledge (e.g., Hodges et al., 1995; Hodges et al., 1992; Saffran \& Schwartz, 1994). Although there was a trend toward greater activity in the temporal lobes during the naming of low-agreement pictures in Experiment 1, the effect was not statistically significant (see Table 1). Furthermore, Wagner et al. (2001) have argued that the LIFG is specifically involved in effortful, or controlled, semantic retrieval; however, semantic retrieval during picture naming is generally not considered to be the result of an effortful search process (e.g., Levelt et al., 1991).

Another potential explanation concerns the domain of task preparation. Using a task-cuing paradigm, Brass and von Cramon (2002) demonstrated that the dorsal posterior region of the LIFG (BA 6/44) is part of a network that responds to task preparation. Specifically, this network is responsible for selecting and implementing a task set that facilitates performance. Thus, it is conceivable that the increased level of response uncertainty present in the low-agreement condition led to an increased level of task preparation. However, this seems to be an unlikely explanation of the difference between the two agreement conditions. In order for subjects to prepare for a change in task set, they need to be aware of the task change. In the present study, the subjects were aware only of the switch between the experimental task (picture naming) and the baseline task (rectangle detection). From their perspective, the two different picture-naming conditions were one and the same. Thus, it seems unlikely that they engaged in different levels of task preparation between the two agreement conditions.

The third explanation is that LIFG activity is related to the demands of selection of information among competing alternatives. This hypothesis rests on the assumption that selection demands are inversely correlated with picture name agreement. Behaviorally, our RT data are consistent with those reported by Kremin et al. (2000). That is, the subjects were able to identify high name agreement pictures more quickly than low name agreement pictures. On the basis of the picture-naming models proposed by Fraisse (1969) and Levelt et al. (1991), this pattern of RT data is not at all surprising. If perceiving an object activates all semantic cohorts automatically, low name agreement objects will activate more candidate names than will high name agreement objects. Thus, the selection process will require more time to evaluate all the competing alternatives before selecting a target item. We propose that whereas the temporal lobes are recruited during retrieval of the semantic cohorts, the LIFG is responsible for mediating this selection mechanism.

More specifically, we propose that LIFG activity is modulated by selection of information on a representation level. That is, LIFG activity is mediated by the degree of selection among competing alternatives on a conceptual level. On the other hand, selection on the response level may be mediated by the anterior cingulate. In other words, the anterior cingulate may be recruited when selection of the appropriate articulatory program for production is required by the task, and that may be why we observed a marginally significant selection effect in the anterior cingulate only in the overt condition in Experiment 1 . This idea is consistent with published findings of dissociations between the anterior cingulate and the LIFG (Barch et al., 2000; Milham et al., 2001; Nelson, Reuter-Lorenz, Sylvester, Jonides, \& Smith, 2003; van Veen, Cohen, Botvinick, Stenger, \& Carter, 2001). For example, in an fMRI investigation of neural activity during a modified Stroop task, Milham and colleagues reported that whereas the dorsolateral and posterior inferior prefrontal cortices respond to selection of competing semantic representations, the anterior cingulate is recruited only when conflict on a response level is present.

Using a working memory task, Nelson et al. (2003) also demonstrated a similar dissociation between leftprefrontal and anterior cingulate activity. They argued that whereas left-prefrontal activity is associated with the selection of relevant representations, anterior cingulate activity increased with response conflict. Finally, using a flanker task, van Veen et al. (2001) investigated whether the anterior cingulate monitors conflict on all levels of processing or whether its response is exclusive to a specific level of processing (e.g., stimulus encoding and response conflict). The authors reported that the anterior cingulate is selectively responsive to response conflict, and not to conflict on the representation level. They suggested that this pattern may be related to the interconnectivity between the motor system and the anterior cingulate. Taken together, these studies have provided strong support for the functional dissociation between the LIFG and the anterior cingulate. On the basis of the present data, however, we must interpret the functional dissociation observed in a picture-naming task with caution: Although the effect was marginal in Experiment 1 $(p=.03)$, the effect was only a trend in Experiment 2 $(p=.11)$. 
Historically, the posterior portion of the LIFG, or Broca's area, has been associated with language, especially language production and syntax, by virtue of its ties to Broca's aphasia. Clinical symptoms of Broca's aphasia typically include slow, dysprosodic, poorly articulated speech, agrammatism (reduced phrase structure, omission and substitution of closed class elements), and problems with confrontation naming (Goodglass, 1993). Recent studies have demonstrated that the link between Broca's aphasia and the so-called Broca's area is tenuous at best: Damage to Broca's area does not reliably result in Broca's aphasia (e.g., Basso, Lecours, Moraschini, \& Vanier, 1985; Mohr et al., 1978). For example, Dronkers, Shapiro, Redfern, and Knight (1992) reported that of the 25 patients tested, lesions to Broca's area did not reliably predict Broca's aphasia (nor did the diagnosis of Broca's aphasia predict damage to Broca's area). Instead, they reported a perfect correlation between lesion location and apraxia of speech, an articulatory deficit commonly associated with Broca's aphasia. In other words, Dronkers et al. demonstrated that the symptom of apraxia of speech, not the syndrome of Broca's aphasia, is correlated with a specific lesion location. Similarly, although the full-blown syndrome of Broca's aphasia rarely results from damage that is limited to the LIFG, it is possible that some symptoms commonly associated with Broca's aphasia and other nonfluent aphasias are, in fact, associated with LIFG damage. Specifically, we propose that some linguistic deficits associated with nonfluent aphasias might be understood as an impairment of a more general selection mechanism. Furthermore, these selection-related deficits should be correlated with the extent of damage to the posterior LIFG.

For example, one common symptom in all language disorders, including the nonfluent aphasias, is an impairment in confrontation naming ability, typically assessed with a picture-naming task (Goodglass, 1993). Although naming errors are a ubiquitous problem with all aphasias, the types of errors in naming vary across patients and, less consistently, across subtypes (Ardila \& Rosselli, 1993). In the context of the picture-naming models presented earlier, this impairment may be under- stood either as a retrieval deficit or as a selection deficit. Whereas some patients may have problems activating the semantic cohorts, other patients may have a selection deficit. When asked to perform a confrontation naming task, the error profiles produced by these patients may be very different. Specifically, we may expect no-response errors from aphasics with a retrieval deficit and semantic paraphasic errors from other aphasics with an inefficient or faulty selection mechanism (e.g., Hillis, Rapp, Romani, \& Caramazza, 1990; Howard \& Orchard-Lisle, 1984). On the basis of the results of this study, we predict that aphasic patients with lesions including the posterior LIFG will show deficits in confrontation naming that are consistent with a selection impairment, whereas aphasic patients with lesions sparing the posterior LIFG will not. The same logic extends to predictions about performance on other linguistic tasks that involve selection among competing alternatives (e.g., ambiguity resolution and verbal fluency).

Thus far, our discussion has focused on selection effects in the context of semantic tasks. It is not clear whether the selection mechanism associated with LIFG activity is limited to semantic knowledge or whether the LIFG serves a more general purpose of selection that generalizes to nonsemantic domains. Data from our lab and others have provided some evidence for the latter claim. For example, we recently tested the idea that selection and maintenance can be dissociated in a study of working memory deficits in brain-damaged patients (Thompson-Schill et al., 2002), using a working memory task in which we were able to manipulate selection demands on an item-by-item basis (Jonides, Smith, Marshuetz, Koeppe, \& Reuter-Lorenz, 1998). On each trial, a group of four letters was presented (e.g., $t, r, p$, and $g$ ), and after a delay, a single-letter probe was presented $(K)$. The subjects had to decide whether the probe letter was a member of the target set on that trial. On high selection trials, the probe appeared in the previous trial's target set; on these trials, we increased competition from an incorrect item by having presented it recently. On low selection trials, the probe did not appear in any recent target set. A variation of this task was first used in neu-

Table 3

Local Maxima of High Selection Demands - Low Selection Demands Contrast Reported in the Present Experiments and in Two Previous Neuroimaging Studies

\begin{tabular}{|c|c|c|}
\hline Study & Task & $\begin{array}{c}\text { Local Maxima } \\
\text { (MNI coordinates [XYZ] } \\
\text { and Brodmann's Area) } \\
\end{array}$ \\
\hline $\begin{array}{l}\text { Thompson-Schill, D’Esposito, } \\
\text { Aguirre, \& Farah (1997) }\end{array}$ & $\begin{array}{l}\text { word generation } \\
\text { picture classification } \\
\text { attribute comparison }\end{array}$ & $\begin{array}{l}-49.49,8.09,33.13 \text { (BA 44) } \\
-38.38,15.30,33.51 \text { (BA 44) } \\
-45.45,3.97,32.92 \text { (BA 44) }\end{array}$ \\
\hline $\begin{array}{l}\text { Thompson-Schill, D’Esposito, } \\
\text { \& Kan (1999) }\end{array}$ & word generation & $-44.44,15.34,24.79$ (BA 44) \\
\hline $\begin{array}{l}\text { Experiment } 1 \\
\quad \text { (line drawings) }\end{array}$ & $\begin{array}{l}\text { covert picture naming } \\
\text { overt picture naming }\end{array}$ & $\begin{array}{ll}-56.25, & 3.75,35.00(\text { BA } 44) \\
-56.25, & 3.75,35.00(\text { BA } 44)\end{array}$ \\
\hline Experiment 2 (photographs) & overt picture naming & $-36.00,24.00,21.00(\mathrm{BA} 45)$ \\
\hline
\end{tabular}


roimaging studies, which reported increased activity in the LIFG for high selection trials (D'Esposito, Postle, Jonides, \& Smith, 1999; Jonides et al., 1998). In our case study of a patient with LIFG damage in the same region as that identified in these imaging studies, the patient showed a severely disproportionate impairment on the high selection trials. The selection effect (i.e., the difference in accuracy between high- and low-selection trials) in this patient was more than six standard deviations above control performance. We also demonstrated functional and stochastic independence of selection ability and working memory capacity across all patients. These data provide support for the hypothesis that selection of information from competing alternatives is a general function of the LIFG. However, the location within the LIFG implicated in this working memory selection task was slightly anterior to the location within the LIFG described in an earlier study. Thus, the possibility for functional heterogeneity within the LIFG (and the prefrontal cortex more generally) remains an open question. For example, it has recently been proposed that whereas the anterior portion of the LIFG (e.g., BAs 47 and 10) are involved in semantic retrieval, the posterior portion of the LIFG (e.g., BAs 44 and 45) may be implicated in selection (see Thompson-Schill, 2003, for a review).

One approach to examining the functional heterogeneity within the LIFG is by asking a related question: Is there a subregion within the LIFG that is consistently activated in different selection tasks? Table 3 summarizes the local maxima within the LIFG that are sensitive to selection manipulations, as reported in previous $\mathrm{fMRI}$ studies and the present experiments. Across six different experiments that used four different experimental tasks and two different response modalities, all local maxima points fall within BAs 44 and 45 . This provides strong evidence that there exists a subregion within the LIFG that is sensitive to the manipulation of selection demands.

The selection account is a viable candidate in explaining and unifying previous inconsistent findings in the picture-naming literature. Furthermore, this account may be extended so as to explain some of the discrepancies in the aphasia literature as well. Aphasia syndromes are best considered as a constellation of symptoms, and a better appreciation of the relation between brain structures and language disorders will arise from investigations that associate structure with specific symptoms (e.g., selection impairments), rather than with a multifaceted syndrome. As we attempt to further understand linguistic deficits, allowing anatomical considerations to take precedence over syndrome classifications may be a more promising way to study the relationship between brain structure and function.

\section{REFERENCES}

Aguirre, G. K., Zarahn, E., \& D'Esposito, M. (1997). Empirical analyses of BOLD fMRI statistics: II. Spatially smoothed data collected under null-hypothesis and experimental conditions. NeuroImage, 5, 199-212.
Ardila, A., \& Rosselli, M. (1993). Language deviations in aphasia: A frequency analysis. Brain \& Language, 44, 165-180.

BAJO, M. T. (1988). Semantic facilitation with pictures and words. Journal of Experimental Psychology: Learning, Memory, \& Cognition, 14, 579-589.

Barch, D. M., Braver, T. S., SABb, F. W., \& Noll, D. C. (2000). Anterior cingulate and the monitoring of response conflict: Evidence from an $\mathrm{fMRI}$ study of overt verb generation. Journal of Cognitive Neuroscience, 12, 298-309.

Barch, D. M., Sabb, F. W., Carter, C. S., Braver, T. S., Noll, D. C., \& COHEN, J. D. (1999). Overt verbal responding during fMRI scanning: Empirical investigations of problems and potential solutions. NeuroImage, 10, 642-657.

Basso, A., Lecours, A. R., Moraschini, S., \& VAnier, M. (1985). Anatomoclinical correlations of the aphasias as defined through computerized tomography: Exceptions. Brain \& Language, 26, 201229.

Bookheimer, S. Y., ZefFiro, T. A., Blaxton, T., Gaillard, W., \& THEODORE, W. (1995). Regional cerebral blood flow during object naming and word reading. Human Brain Mapping, 3, 96-106.

BRASS, M., \& VON CRAMON, D. Y. (2002). The role of the frontal cortex in task preparation. Cerebral Cortex, 12, 908-914.

Caramazza, A., Hillis, A. E., Rapp, B. C., \& Romani, C. (1990). The multiple semantics hypothesis: Multiple confusions? Cognitive Neuropsychology, 7, 161-189.

Carter, C. S., Macdonald, A. M., Botvinick, M., Ross, L. L., Stenger, V. A., Noll, D., \& Cohen, J. D. (2003). Parsing executive processes: Strategic vs. evaluative functions of the anterior cingulate cortex. Proceedings of the National Academy of Sciences, 97, 19441948.

Cohen, J. D., MacWhinney, B., Flatt, M., \& Provost, J. (1993). PsyScope: An interactive graphic system for designing and controlling experiments in the psychology laboratory using Macintosh computers. Behavior Research Methods, Instruments, \& Computers, 25, 257-271.

Demb, J. B., Desmond, J. E., Wagner, A. D., Vaidya, C. J., Glover, G. H., \& GABRIELI, J. D. (1995). Semantic encoding and retrieval in the left inferior prefrontal cortex: A functional MRI study of task difficulty and process specificity. Journal of Neuroscience, 15, 58705878.

Démonet, J. F., Chollet, F., Ramsay, S., Carde bat, D., Nespoulous, J. L., WISE, R., RASCOL, A., \& FRACKOWIAK, R. (1992). The anatomy of phonological and semantic processing in normal subjects. Brain, 115, 1753-1768.

D’Esposito, M., Postle, B. R., Jonides, J., \& Smith, E. E. (1999). The neural substrate and temporal dynamics of interference effects in working memory as revealed by event-related functional MRI. Proceedings of the National Academy of Sciences, 96, 7514-7519.

de Zubicaray, G. I., Wilson, S. J., McMahon, K. L., \& Muthiah, S. (2001). The semantic interference effect in the picture-word paradigm: An event-related fMRI study employing overt responses. Human Brain Mapping, 14, 218-227.

DronKers, N. F., ShAPIRO, J. K., RedFERn, B., \& KNIGHT, R. T. (1992). The role of Broca's area in Broca's aphasia. Journal of Clinical \& Experimental Neuropsychology, 14, 52-53.

Etard, O., Mellet, E., Papathanassiou, D., Benali, K., Houde, O., Mazoyer, B., \& Tzourio-Mazoyer, N. (2000). Picture naming without Broca's and Wernicke's area. NeuroReport, 11, 617-622. Evans, A. C., Collins, D. L., Mills, S. R., Brown, E. D., Kelly, R. L., \& Peters, T. M. (1993, November). 3D statistical neuroanatomical models from 305 MRI volumes. Paper presented at the IEEENuclear Science Symposium and Medical Imaging Conference, San Francisco.

Fraisse, P. (1969). Why is naming longer than reading? Acta Psychologica, 30, 96-103.

Glaser, W. R. (1992). Picture naming. Cognition, 42, 61-106.

Goodglass, H. (1993). Understand aphasia. San Diego: Academic Press.

Goodglass, H., \& STUSS, D. T. (1979). Naming to picture versus description in three aphasic subgroups. Cortex, 15, 199-211. 
Hillis, A. E., Rapp, B. C., Romani, C., \& Caramazza, A. (1990). Selective impairments of semantics in lexical processing. Cognitive Neuropsychology, 7, 181-243.

Hodges, J. R., Graham, N., \& Patterson, K. (1995). Charting the progression in semantic dementia: Implications for the organisation of semantic memory. Memory, 3, 463-495.

Hodges, J. R., PAtterson, K., Oxbury, S., \& Funnell, E. (1992). Semantic dementia. Progressive fluent aphasia with temporal lobe atrophy. Brain, 115, 1783-1806.

Howard, D., \& ORChaRd-Lisle, V. (1984). On the origin of semantic errors in naming: Evidence from the case of a global aphasic. Cognitive Neuropsychology, 1, 163-190.

HutTENLOCHER,J., \& KUBICE K, L. F. (1984). The source of relatedness effects on naming latency. Journal of Experimental Psychology: Learning, Memory, \& Cognition, 9, 486-496.

Ilmberger, J., Eisner, W., Schmid, U., \& Reulen, H. J. (2001). Performance in picture naming and word comprehension: Evidence for common neuronal substrates from intraoperative language mapping. Brain \& Language, 76, 111-118.

Jonides, J., Smith, E. E., Marshuetz, C., Koeppe, R. A., \& ReuterLORENZ, P. A. (1998). Inhibition in verbal working memory revealed by brain activation. Proceedings of the National Academy of Sciences, 95, 8410-8413.

KoHn, S. E., \& Goodglass, H. (1985). Picture-naming in aphasia. Brain \& Language, 24, 266-283.

Kremin, H., Hamerel, M., Dordain, M., De Wilde, M., \& PerRIER, D. (2000). Age of acquisition and name agreement as predictors of mean response latencies in picture naming of French adults. Brain \& Cognition, 43, 286-291.

Levelt, W. J. M., Schriefers, H., Vorberg, D., Meyer, A. S., PechMANN, T., \& HAVINGA, J. (1991). The time course of lexical access in speech production: A study of picture naming. Psychological Review, 98, 122-142.

LUPKER, S. J. (1988). Picture naming: An investigation of the nature of cateogrical priming. Journal of Experimental Psychology: Learning, Memory, \& Cognition, 14, 444-455.

McCauley, C., Parmelee, C. M., Sperber, R. D., \& Carr, T. H. (1980). Early extraction of meaning from pictures and its relation to conscious identification. Journal of Experimental Psychology: Human Perception \& Performance, 6, 265-276.

Milham, M. P., Banich, M. T., Webb, A., Barad, V., Cohen, N. J., WSZAleK, T., \& KRAMER, A. F. (2001). The relative involvement of anterior cingulate and prefrontal cortex in attentional control depends on nature of conflict. Cognitive Brain Research, 12, 467-473.

Mohr, C. M., Pessin, M. S., Finkelstein, S., Funkenstein, H. H., Duncan, G. W., \& Davis, K. R. (1978). Broca aphasia: Pathologic and clinical. Neurology, 28, 311-324.

Murtha, S., Chertkow, H., Beauregard, M., \& Evans, A. (1999). The neural substrate of picture naming. Journal of Cognitive Neuroscience, 11, 399-423.

Nelson, J. K., Reuter-Lorenz, P. A., Sylvester, C.-Y. C., Jonides, J., \& SMith, E. E. (2003). Dissociable neural mechanisms underlying response-based and familiarity-based conflict in working memory. Proceedings of the National Academy of Sciences, 100, 1117111175.

OLDFIELD, R. (1971). The assessment and analysis of handedness: The Edinburgh Inventory. Neuropsychologia, 9, 97-113.

Petersen, S. E., Fox, P. T., Posner, M. I., Mintun, M., \& Raichle, M. E. (1988). Positron emission tomographic studies of the cortical anatomy of single-word processing. Nature, 331, 585-589.

Raichle, M. E., Fiez, J. A., Videen, T. O., Macleod, A. M., Pardo, J. V., Fox, P. T., \& Petersen, S. E. (1994). Practice-related changes in human brain functional anatomy during nonmotor learning. Cerebral Cortex., 4, 8-26.
RATCLIFF, R., \& MCKoON, G. (1996). Bias effects in implicit memory tasks. Journal of Experimental Psychology: General, 125, 403-421. Robinson, K. M., Grossman, M., White-De vine, T., \& D'EspoSITO, M. (1996). Category-specific difficulty naming with verbs in Alzheimer's disease. Neurology, 47, 178-182.

SAFFRAN, E. M., \& SCHWARTZ, M. F. (1994). Of cabbages and things: Semantic memory from a neuropsychological perspective-A tutorial review. In C. Umiltà \& M. Moscovitch (Eds.), Attention and performance XV: Conscious and nonconscious information processing (pp. 507-536). Hillsdale, NJ: Erlbaum.

Salmelin, R., Hari, R., Lounasmaa, O. V., \& Sams, M. (1994). Dynamics of brain activation during picture naming. Nature, 368, 463465.

Sergent, J., Ohta, S., \& MacDonald, B. (1992). Functional neuroanatomy of face and object processing: A positron emission tomography study. Brain, 115(Pt. 1), 15-36.

SNODGRASS, J. G., \& VANDERWART, M. (1980). A standardized set of 260 pictures: Norms for name agreement, image agreement, familiarity, and visual complexity. Journal of Experimental Psychology: Human Learning \& Memory, 6, 174-215.

Sperber, R. D., McCauley, C., Ragain, R. D., \& Weil, C. M. (1979). Semantic priming effects on picture and word processing. Memory \& Cognition, 7, 339-345.

Spitzer, M., Kwong, K. K., Kennedy, W., Rosen, B. R., \& BelLIVEAU, J. W. (1995). Category-specific brain activation in fMRI during picture naming. NeuroReport, 6, 2109-2112.

THOMPSON-SCHILL, S. L. (2003). Neuroimaging studies of semantic memory: Inferring "how" from “where." Neuropsychologia, 41, 280292.

Thompson-Schill, S. L., D’Esposito, M., Aguirre, G. K., \& FArAh, M. J. (1997). Role of left inferior prefrontal cortex in retrieval of semantic knowledge: A reevaluation. Proceedings of the National Academy of Sciences, 94, 14792-14797.

THOMPSON-SCHILL, S. L., D'EsPosito, M., \& KAN, I. P. (1999). Effects of repetition and competition on prefrontal activity during word generation. Neuron, 23, 513-522.

Thompson-Schill, S. L., Jonides, J., Marshuetz, C., Smith, E. E., D’Esposito, M., Kan, I. P., KNight, R. T., \& Swick, D. (2002). Effects of frontal lobe damage on interference effects in working memory. Cognitive, Affective \& Behavioral Neuroscience, 2, 109-120. ThOMPSON-Schill, S. L., SWICK, D., FARAH, M. J., D'Esposito, M., KAN, I. P., \& KNIGHT, R. T. (1998). Verb generation in patients with focal frontal lesions: A neuropsychological test of neuroimaging findings. Proceedings of the National Academy of Sciences, 95, 15855-15860.

van Veen, V., Cohen, J. D., Botvinick, M., Stenger, V. A., \& CARTER, C.S. (2001). Anterior cingulate cortex, conflict monitoring, and levels of processing. NeuroImage, 14, 1302-1308.

Wagner, A. D., Pare-Blagoev, E. J., Clark, J., \& Poldrack, R. A. (2001). Recovering meaning: Left prefrontal cortex guides controlled semantic retrieval. Neuron, 31, 329-338.

Warrington, E. K., \& Shallice, T. (1984). Category specific semantic impairments. Brain, 107(Pt. 3), 829-854.

Whatmough, C., Chertkow, H., Murtha, S., \& Hanratty, K. (2002). Dissociable brain regions process object meaning and object structure during picture naming. Neuropsychologia, 40, 174-186.

WORSLEY, K. J., \& FRISTON, K. (1995). Analysis of fMRI time-series revisited-again. NeuroImage, 2, 173-182.

Zarahn, E., Aguirre, G. K., \& D’Esposito, M. (1997). Empirical analyses of BOLD fMRI statistics: I. Spatially unsmoothed data collected under null-hypothesis conditions. NeuroImage, 5, 179-197.

(Manuscript received June 19, 2003; revision accepted for publication January 30, 2004.) 